\title{
A ética no serviço de catalogação: uma revisão bibliográfica
}

\author{
Edinei Antonio Moreno \\ Universidade do Estado de Santa Catarina - UDESC, Brasil
}

\section{REVIEW}

\section{Resumo}

Objetivo. O estudo analisa a presença da ética no serviço de catalogação realizado pelo bibliotecário.

Método. O estudo se utilizou do método de revisão bibliográfica.

Resultados. Nos resultados se obteve a conceituação do termo ética; afirmação da importância das tecnologias da informação e comunicação para o serviço de catalogação e os sistemas de recuperação da informação; o papel ético do bibliotecário no serviço de catalogação.

Conclusões. O presente estudo de revisão bibliográfica possibilitou apresentar propostas para futuros estudos na área da Biblioteconomia e Ciência da Informação.

Palavras-chave

Sistema de recuperação da informação ; Ética ; Serviço de catalogação ; Papel do bibliotecário

\section{Ethics in service cataloging: a literature review}

\author{
Abstract \\ Objective. The study analyzes the presence of ethics in cataloging service performed by the librarian. \\ Method. The study used the method of literature review. \\ Results. The results obtained are the conceptualization of ethics term ; affirmation of the importance of information technologies \\ and communication for cataloging service and information retrieval systems ; the ethical role of the librarian in cataloging service. \\ Conclusions. The bibliographic review allowed to make proposals for future studies in the field of Library and Information \\ Science.
}

\section{Keywords}

Information retrieval system ; Ethics ; Cataloging service ; Librarian role

\section{Introdução}

A ética está presente no cotidiano das pessoas e é um tema que vem ao longo da história sendo formado, discutido e transformado pela humanidade. Sendo assim, a ética participa nas decisões e nas atividades do ser humano, seja em casa, no trabalho, escola e outros, é uma conduta individual perante a sociedade. A análise sobre a ética nas profissões mostra uma discussão que aborda um conjunto de princípios que podem ser utilizados como fundamentos para compreender e justificar as escolhas a serem feitas para orientar as ações ou conduta do homem em suas atividades e o convívio com outros.

Em se tratando das atividades do profissional bibliotecário, em específico, no serviço de catalogação (tratamento da informação), para posterior recuperação pelo usuário, a ética esbarra nas questões de como esses serviços são realizados, ou seja, a utilização de uma linguagem controlada nos sistemas de recuperação da informação, bem 
como, do agir ético do bibliotecário. O desafio ético do profissional bibliotecário está em diminuir as ambiguidades bastante comuns na linguagem natural, utilizadas habitualmente pelos usuários dos sistemas de recuperação da informação, e introduzi-las quando do serviço de catalogação da informação nos sistemas.

A catalogação é uma das atividades mais importante que são realizadas pelos bibliotecários e, como produto, se oferece ao usuário a possibilidade de acessar a informação em um catálogo (online ou não), por meio do documento completo ou a sua localização. Nesse sentido, a pergunta que se formou como interesse de resposta foi, "nas atividades de tratamento da informação (catalogação) a ética se faz presente?

O artigo possui como objetivo geral mostrar a pertinência da ética nas atividades de catalogação da informação, realizadas pelo bibliotecário. Com base nisso, o presente trabalho está estruturado, além dessa seção introdutória, pelas seções: (2) Ética e o bibliotecário; (3) Sistemas de recuperação da informação; (4) Ética no serviço de catalogação; (5) Considerações finais e por fim as referências utilizadas.

\section{1 Ética e o bibliotecário}

No sentido mais amplo, ética formaliza o que é certo e o que é errado, o que se pode ou o que não se pode fazer em face das normas adotadas pela sociedade ou grupo a que pertence o indivíduo. Etimologicamente, a palavra "ética" se origina do grego "ethos", que significa morada, lugar onde vivemos. O tema também responde ao "significado de hábitos, costumes e valores, modo de ser que um grupo vai adquirindo ao longo da vida. Os romanos traduziam para o termo latino "mos", "moris" (que mantém o significado de "ethos") dos quais provém "moralis", que deu origem a palavra em português, moral”. (MARCONDES, 2008, p. 9).

Os conceitos de moral e ética acabam se confundindo e seus significados são quase idênticos. A ética estuda os valores e a conduta do homem na sociedade, preconizando os direitos e deveres decorrentes de tal conduta, pressupondo a concepção de bem agir e de bem fazer. A ética reflete sobre a vida moral em si, centrando-se nos objetos morais em todas as suas formas de evoluir (visão universal). Ainda sobre a ética pode-se dizer que é um tipo de saber normativo que orienta e fundamenta as ações dos seres humanos, enquanto que a moral orienta as suas ações para casos concretos. A moral refere-se as ações desenvolvidas (normas de comportamento) em um universo concreto, geográfica e temporariamente delimitado (visão local). Portanto, a ética é o momento reflexivo sobre o porquê de determinadas ações, ou seja, o fundamento das ações humanas; e a moral é o conjunto de normas que conduzem as ações dos indivíduos em sociedade.

Existindo essas coincidências etimológicas, deve-se traçar, antes de conceituar ética, uma definição, mesmo que tênue, sobre moral. Para Cortina e Navarro (2005, p. 20), chamamos de "moral" o conjunto de princípios, normas e valores que cada geração transmite à geração seguinte na confiança de que se trata de um bom legado de orientações sobre o modo de se comportar para viver uma vida boa e justa. A pergunta da moral seria, "o que devemos fazer?"; ao passo que a questão central da ética seria antes, "Por que devemos?"

Para a proposta desse artigo, é importante esclarecer a definição de ética. No decorrer da história, diversas foram as abordagens e os conceitos dados por filósofos e estudiosos sobre o tema ética. O quadro 1 traz algumas reflexões:

\section{Origem}

As inquietações a respeito da Ética se baseavam em perguntar "em que consiste a verdadeira virtude e noção do bem do indivíduo". Afirmava que ninguém que conhecia realmente o bem, poderia agir mal. "Daí a importância da educação dos cidadãos como tarefa ética primordial, uma vez que só se contarmos com cidadãos verdadeiramente sábios poderemos esperar que eles sejam bons cidadãos."

Quadro 1 : Reflexões de ética (continua).

Fonte: (SÁ (2001); CHAUI (2002); SINGER (2002); CORTINA; NAVARRO (2011)). 


\begin{tabular}{|c|c|}
\hline \multicolumn{2}{|r|}{ Origem } \\
\hline Platão & $\begin{array}{l}\text { Dizia que "a moral devia ser um conhecimento que dirige a vida do indivíduo e da } \\
\text { comunidade, do cidadão e da polis. Esse conhecimento levaria o ser humano à } \\
\text { felicidade". Ainda dizia que "os indivíduos só podem ser felizes numa sociedade bem } \\
\text { organizada. Por isso, o que é bom e justo para o indivíduo não pode ser diferente do } \\
\text { que é bom e justo para a comunidade geral se manter feliz". }\end{array}$ \\
\hline Aristóteles & $\begin{array}{l}\text { Ética se baseava no encontro da verdadeira felicidade e investigava no que ela } \\
\text { consistia. }\end{array}$ \\
\hline Santo Agostinho & $\begin{array}{l}\text { Afirmava a ideia em que a moral é o conjunto de orientações éticas, cujo objetivo é a } \\
\text { felicidade. Se resumia a "amar a Deus sobre todas as coisas e ao próximo como a ti } \\
\text { mesmo". }\end{array}$ \\
\hline Tomás de Aquino & $\begin{array}{l}\text { Considerava que todo indivíduo era capaz de compreender conceitos básicos como } \\
\text { "conservar a própria vida, satisfazer as necessidades corporais, atender ás } \\
\text { inclinações sociais e culturais, pois esses princípios eram inerentes neles". }\end{array}$ \\
\hline \multicolumn{2}{|r|}{ Idade Moderna } \\
\hline Rosseau & $\begin{array}{l}\text { Expõe a ideia de que "nascemos bons e puros, dotados de generosidade e de } \\
\text { benevolência para com os outros". }\end{array}$ \\
\hline Immanuel Kant & $\begin{array}{l}\text { Afirma o papel da razão na Ética, que "não existia bondade natural. Por natureza, o } \\
\text { homem é egoísta, ambicioso, destrutivo, agressivo, cruel, ávido de prazeres que } \\
\text { nunca o saciam, pelos quais matam, mentem, e roubam". }\end{array}$ \\
\hline \multicolumn{2}{|r|}{ Idade contemporânea } \\
\hline Sá & $\begin{array}{l}\text { A ética, ao analisar a conduta humana, leva em consideração os meios que devem } \\
\text { ser empregados para que essa conduta seja sempre revertida em benefício do } \\
\text { homem, cuidando das formas ideais de ação humana e buscando a essência do ser. }\end{array}$ \\
\hline Singer & $\begin{array}{l}\text { A preocupação natural em defender os meus interesses tende a se alargar, quando } \\
\text { penso eticamente nos interesses alheios. } \\
\text { Considerar que a ética implica necessariamente, em certo sentido, um ponto de vista } \\
\text { universal é uma forma mais natural e menos confusa de abordar essas questões. } \\
\text { Ver as coisas eticamente é uma forma de transcender as nossas preocupações } \\
\text { subjetivas e de nos identificarmos com o ponto de vista mais objetivo possível. }\end{array}$ \\
\hline
\end{tabular}

Quadro 1 : Reflexões de ética (conclusão). Fonte: (SÁ (2001); CHAUI (2002); SINGER (2002); CORTINA; NAVARRO (2011)).

Distintas são as definições e os estudos da ética no decorrer dos anos. No entanto, como definição para este artigo, considerar-se-á que a "ética avalia a conduta humana perante o ser e os seus semelhantes, parte do pressuposto que o julgamento das ações devem considerar as circunstâncias de todos os envolvidos, uma vez que confronta 0 desempenho humano em relação às normas comportamentais estabelecidas em determinado contexto social".

Ao associarmos a ética como forma de conduta socialmente estabelecida, levantando o tema profissional bibliotecário, remetemos ao código de conduta desta profissão, denominado no Brasil de "Código de Ética". O profissional bibliotecário também possui padrões éticos a serem seguidos no decorrer de sua vida, dentro ou fora de uma unidade de informação. O Código de Ética do Bibliotecário Brasileiro foi criado a partir de 1960 pela Federação Brasileira de Associações de Bibliotecários - FEBAB. O Código de Ética possibilitou a manifestação de um mundo social onde existem prestadores dos serviços da informação, usuários finais e outros. Na atualidade, o código de ética do bibliotecário vigente foi instituído em 11 de janeiro de 2002. Ele dispõe sobre o Código de Ética do Conselho 
Federal de Biblioteconomia, apresentado por meio da Resolução do Conselho Federal de Biblioteconomia - CFB, n. 42. Constituído por 20 artigos, possui por objetivo fixar normas de conduta para as pessoas físicas e jurídicas que exerçam as atividades profissionais de biblioteconomia. O bibliotecário caracteriza sua função como um prestador de serviços à sociedade, de comunicação e contato direto e indireto com o público (usuários). A regulamentação profissional propicia ao bibliotecário privilegiar o cumprimento da função social das unidades, sistemas e serviços de informação. Para os autores Cuartas, Pessoa e Costa (2003), o código de ética para o profissional bibliotecário implica recompor o referencial de valores básicos de orientação do comportamento e reconhecer que, de nada vale criar normas, se a conduta pessoal não se pautar por elas. O profissional bibliotecário, em suas atividades, necessita agir eticamente, seja no tratamento, guarda e disseminação da informação, seja no respeito com o usuário e colegas de profissão.

Desta forma, o presente estudo visa identificar, por meio de revisão bibliográfica, a presença da ética na atividade de catalogação da informação, realizada pelos bibliotecários. Sendo assim, nas seções seguintes serão abordados os assuntos pertinentes aos sistemas de recuperação da informação e a discussão da presença da ética no serviço de catalogação.

\section{Sistemas de recuperação da informação}

A partir do momento em que a informação foi registrada em um suporte físico (impresso, por exemplo) foi possível transportá-la. E ainda, a conversão do formato impresso para o formato digital, principalmente dentro do contexto do trabalho em rede, possibilitou que a informação fosse rapidamente transportada de um lugar a outro em curtíssimo espaço de tempo e, desse processo, elementos suficientes para a tomada de decisões e a construção do conhecimento fossem oportunizados. Os Sistemas de Informação e Sistemas de Recuperação de Informação, nada mais são que serviços de informação que processam dados (entrada) e fornecem informações (saídas). A informação, na verdade, é indispensável para toda e qualquer atividade humana, sendo, cada vez mais, vista como uma força importante e poderosa (ARAUJO, 1995).

Considerando o contexto da Sociedade da Informação, onde mais do que nunca, esta sociedade se estrutura em informação e tecnologia e a informação tornou-se elemento fundamental, o desenvolvimento de Sistemas de Recuperação da Informação (SRl's) que deem conta de disponibilizar todo esse volume informacional assume o mesmo grau de importância. Podemos afirmar que o objetivo da organização e da gestão da informação consiste na recuperação e o uso eficiente das informações. Conforme destaca Araújo (1995), possibilitar o acesso às informações registradas nos documentos, de forma rápida e precisa, é uma das funções dos SRl's. Segundo Triska (2008, p. 101), diante do volume crescente de registros informacionais, "as ferramentas de busca destes registros passam a ter um papel de destaque no processo de recuperação destes registros de informação", essas ferramentas de busca compõem os SRl's e estão se tornando bastante populares, principalmente com a utilização da Internet.

Partindo do pressuposto de que a informação é capaz de transformar as estruturas mentais, ou seja, de gerar conhecimento novo no indivíduo, deduzimos que os SRl's, à medida que possibilitam o acesso a informação, são elementos essenciais no processo para o desenvolvimento da Ciência. O desenvolvimento da Ciência acontece de forma sistemática, em que um novo conhecimento é gerado com base em um conhecimento anterior, é nesse processo de acessar a produção científica já produzida que os SRl's se destacam. Esse entendimento vai ao encontro à percepção de Ahmed (2005), para este autor o conhecimento precisa ser trocado, precisa ser acessado eficientemente por equipes que não estão necessariamente alocados no mesmo ambiente. $O$ autor coloca ainda que, o reúso do conhecimento pode ser utilizado na adaptação de soluções anteriores aos problemas atuais, além de servirem como parâmetro de orientação aos novos profissionais.

Os SRl's se utilizam de metodologias de indexação e de taxonomias como ferramentas que possibilitem a recuperação da informação. A indexação consiste na atribuição de termos/descritores que representem os assuntos contidos nos documentos (VIEIRA, 1988). Enquanto que a taxonomia é uma classificação sistemática dos conceitos, organizados hierarquicamente, que possibilita a recuperação por navegação (CAMPOS; GOMES, 2008). No processo de indexação e de taxonomias, há o predomínio da utilização das linguagens controladas / linguagens documentárias ou vocabulários controlados em detrimento da linguagem natural. O paradigma dos SRI's está em se diminuir as ambiguidades bastante comuns na linguagem natural. 
Como complicador do processo de recuperação da informação, pode-se citar a dificuldade dos usuários no domínio dos vocabulários controlados, bem como, a dificuldade por parte dos profissionais envolvidos (bibliotecários, documentalistas, engenheiros designers) em converter a linguagem natural - geralmente utilizada pelos usuários dos sistemas - em linguagem controlada. Esse fator recai em paradigmas de questão "cultural" - como sendo algo complexo e decisivo no processo de organização da informação; quanto na questão dos "profissionais" - como trabalhar com estereótipos culturais em categorias tão formais e/ou taxonomias culturais.

A vertente temática da organização da informação, por lidar com a questão do conteúdo informacional, que os aspectos éticos do exercício profissional atuam de forma determinante, pois é no conjunto de produtos, processos e instrumentos destinados a representar tematicamente o documento, que a dimensão dos valores do profissional pode estar mais seriamente envolvida (GUIMARÃES, 2006 apud GOMES, BOTTENTUIT, OLIVEIRA, 2009).

A garantia de acesso as informações de maneira globalizada é desenvolvida em valores que impactam nos processos, produtos e instrumentos da área e na atuação profissional. Parte da premissa que os indivíduos precisam de tipos diferentes de informações e meios de obtê-la, surge daí, a grande complexidade nos processos de organização da informação, mas por outro, a possibilidade de uma maior visibilidade para os usuários. Não se pode negar que os avanços tecnológicos influenciam a área de informação e conduzem à pesquisa de novas técnicas de representação e recuperação de conteúdo. O contexto tecnológico atual possui a tendência para o desenvolvimento de sistemas inteligentes de recuperação de informação com base em processamento de linguagem natural, isso por consequência da disponibilidade de documentos completos em máquina e da necessidade de interfaces voltadas para o interagente final. Os sistemas de recuperação exigem, para isso, modelos de representação do conhecimento que possibilitem contextualizar os significados expressos nos textos armazenados

A melhoria da eficácia dos serviços de recuperação da informação depende ainda de estudos mais aprofundados em diversas áreas do conhecimento, englobando todos os processos de organização da informação. Como vimos, mesmo diante de tantos desafios, quanto maior o volume informacional, maior será a necessidade de se estabelecer uma padronização na linguagem utilizada nos SRl's, pois é através da utilização das linguagens documentárias que se obtém maior eficácia na recuperação da informação.

Nesses termos, pela relevância que os SRI's possuem no contexto das bibliotecas, a seção seguinte mostrará os resultados da pesquisa bibliográfica no que se refere a presença da ética no serviço de catalogação para os SRI's.

\section{3 Ética no serviço de catalogação}

Para toda biblioteca, além de possuir as funções de disseminar a informação e ampliar o acesso à cultura, é imprescindível que se ofereça produtos e serviços com a máxima qualidade, ou seja, a unidade de informação que queira atingir as expectativas informacionais de seus usuários necessita de um bom sistema de gerenciamento e recuperação do acervo. Além deste, os profissionais que atuam na área da biblioteconomia necessitam dominar competências e habilidades sociais, técnicas e tecnológicas, condições essas necessárias para alcançar os objetivos sociais e éticos que a profissão determina.

\section{É preciso reconhecer que para haver mudança qualitativa na forma como as pessoas vivem é importante superar o comodismo, ou seja, é necessária uma avaliação de como a realidade se apresenta em toda sua complexidade e de como essa realidade poderia ser melhorada. (ARANALDE, 2005).}

A atuação do profissional bibliotecário, considerando os distintos contextos socioeconômicos, se dá em todos os níveis e para todos os seguimentos sociais. Esse profissional deverá atingir os objetivos da instituição no qual atua, bem como, os anseios informacionais dos diferentes públicos. Vergueiro (1999, p. 9) afirma que, "os bibliotecários devem coletar e fornecer, sem quaisquer tipos de restrições, todas as informações necessárias a seus usuários, sem questionar as aplicações que eles farão das informações recebidas". A responsabilidade social e a ética no bibliotecário se traduz principalmente com o dever de gerir informações da melhor maneira possível, oferecendo-as aos usuários com o máximo de qualidade. Aranalde (2005) retrata que toda postura ética requer avaliação crítica de uma dada situação tomada como insatisfatória e escolha dos melhores meios para modificá-la efetivamente. Para que um bom sistema de recuperação da informação possa atender todas as expectativas e exercer sua função com 
excelência é necessário que o serviço de tratamento da informação (catalogação) seja realizado por um profissional que tenha como foco o usuário.

Sendo assim, para esclarecimento, Raju e Raju (2006) concebem a catalogação enquanto processo de preparação de entradas para um catálogo, com base em um conjunto de regras, de tal forma a permitir ao usuário o conhecimento dos documentos disponíveis e de sua respectiva localização. Em outra definição, Sanchez Luna (2004), aborda a catalogação como um grande universo de tratamento documental, identificando o documento em função de suas características formais e de seu conteúdo, tais como o autor, o título, o local de publicação, a editora, ano de publicação, assim como o tema da obra. Podemos dizer que a catalogação é a operação que consiste em descrever a coleção de livros ou quaisquer tipos de materiais que fazem parte do acervo de uma unidade informacional.

Como percebido, o serviço de catalogação permite ao bibliotecário gerenciar a informação com o único objetivo de superar as expectativas informacionais dos usuários de forma que se recupere a informação em sua totalidade, quando do acesso ao sistema de recuperação da informação (catálogo proveniente do serviço de catalogação). 0 produto final do serviço de catalogação deverá atender o usuário, pois é o usuário que usufrui do sistema em busca de informações e da geração de novos conhecimentos.

O serviço de catalogação é a especificação detalhada do material bibliográfico de modo que o bibliotecário possa inserir as informações no sistema de recuperação, possibilitando ao usuário acessar, sem dificuldades, o documento desejado. Na realização do tratamento das informações é que se apresenta a postura ética requerida de um profissional da informação (bibliotecário, neste caso), que inclui a busca das melhores práticas para a organização, tratamento, armazenamento e disseminação da informação, tendo em vista as necessidades e anseios dos usuários, bem como, a missão social da instituição que atua.

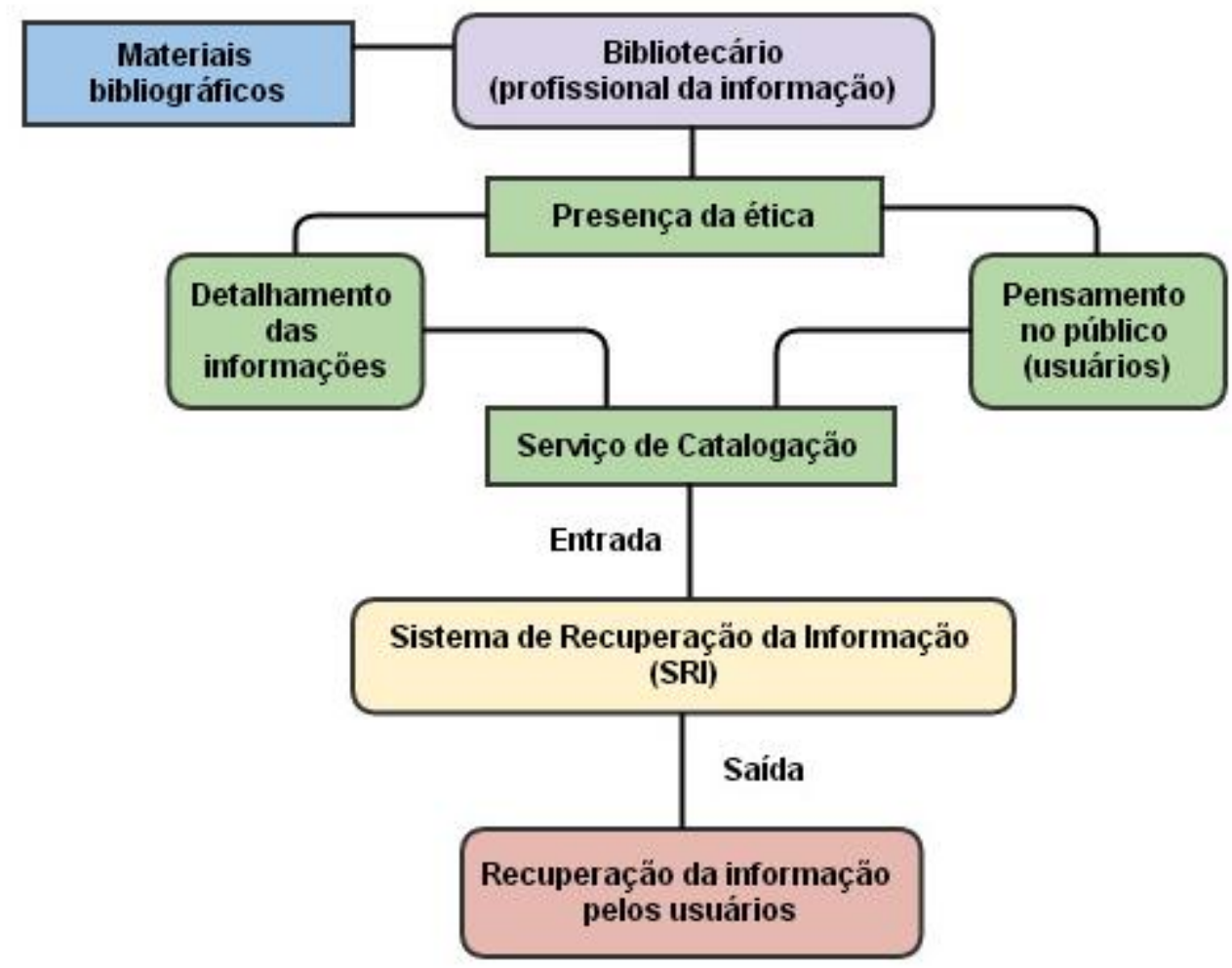

Figura 1 : Presença da ética na catalogação

Fonte: O autor (2014) 
Por possuir características sociais, não há dúvidas que a ética se faz presente nas atividades do bibliotecário, principalmente na catalogação, por essa exigir que a função de detalhamento das informações permita expandir e facilitar o acesso das informações a todos os envolvidos.

A ética faz parte da competência profissional, do domínio dos conhecimentos necessários para o indivíduo desempenhar seu papel na sociedade, articulado com o domínio das técnicas e das estratégias para realização de seu trabalho, inclusive do bibliotecário. (MISCHIATI; VALENTIM, 2005).

O bibliotecário precisa sair de sua "zona de conforto" e pensar em todos os usuários que acessarão determinada informação, procurando assim, agir em benefício da sociedade e bem estar de seu usuário.

A essência do princípio da igualdade na consideração de interesses exige que se atribua o mesmo peso, nas nossas deliberações morais, aos interesses semelhantes de todos os afetados pelas nossas ações. É certo que só podemos saber até onde a igualdade na consideração de interesses nos leva quando soubermos quais são os interesses das outras pessoas, e esses podem variar consoante as suas capacidades ou outras características. (SINGER, 2002).

Fica claro que o bibliotecário precisa conhecer e pensar no público que o serviço de catalogação atingirá, pois os sistemas de recuperação da informação são apenas o canal de ligação entre o usuário e a informação tratada. Quando esse profissional age em benefício comum do seu público e em suas funções consegue transcender as expectativas dos usuários, estará, com certeza, agindo eticamente, conforme sua profissão o exige.

\section{Considerações finais}

O estudo proposto neste artigo tinha por objetivo identificar a presença da ética no serviço de catalogação efetuados pelo profissional bibliotecário.

Na primeira situação foi possível definir um conceito de ética que delineou o estudo, proporcionando identificar em quais situações a ética estava presente nas atividades de catalogação. O conceito definido, após alguns aspectos históricos abordados sobre o tema, foi que a "ética avalia a conduta humana perante o ser e os seus semelhantes, parte do pressuposto que o julgamento das ações devem considerar as circunstâncias de todos os envolvidos, uma vez que confronta o desempenho humano em relação às normas comportamentais estabelecidas em determinado contexto social".

Por segundo, com o avanço das tecnologias e a crescente explosão informacional, os sistemas de recuperação da informação se fazem importantes nesse novo contexto. Vimos que os SRl's são ferramentas de entrada e saída de informações; as entradas são realizadas pelos profissionais da informação (bibliotecário) e a saída é feita quando o usuário busca a informação no sistema. Para os SRl's se mostrarem efetivos é necessário que o serviço de catalogação da informação seja realizado com o propósito único de satisfazer o usuário. A tarefa de tratamento da informação precisa ser realizada propondo englobar várias abordagens com o intuito de facilitar seu acesso. Para esse fim, o bibliotecário precisa agir eticamente, verificando conhecer o público que se destina a informação, bem como, as necessidades destes usuários.

Desta forma, se verificou a existência da ética no serviço de catalogação realizado pelos bibliotecários. Estes profissionais, ao realizar a atividade de catalogação, precisam conhecer todos os aspectos que se relacionam com os usuários, tais como, quais as necessidades informacionais, características de uso da informação e situação socioeconômica e cultural. O bibliotecário precisa sair do comodismo para saber gerenciar, tratar e especificar, eticamente, as informações para os SRI's, de forma a garantir a recuperação efetiva deste material.

Como conclusão final, a ética se faz presente na atividade de catalogação, pois essa tarefa, realizada pelo bibliotecário, atingirá uma sociedade variada e definirá se os SRI's contribuem eficazmente no momento da busca de informações pelos usuários.

Esse trabalho possibilitou acentuar algumas lacunas entre a informação e o usuário, desta forma, como propostas para futuros estudos se indica: a) verificar junto a um grupo de bibliotecários quais as dificuldades na execução do serviço de catalogação; b) avaliar junto aos usuários a utilização de um determinado Sistema de Recuperação da Informação. Esses são alguns apontamentos que surgiram durante a execução desse artigo, cabe salientar que a ética está presente nas atividades do bibliotecário, no entanto, um estudo aprofundado de como essa prática é abordada pelos profissionais da informação seria de grande avalia. 


\section{Referências}

AHMED, Saeema. Encouraging reuse of design knowledge: a method to index knowledge. Design Studies, v. 26, n. 6, p. 565-592, nov., 2005.

ARANALDE, Michel M. A questão ética na atuação do profissional bibliotecário. Em questão, Porto Alegre, v. 11, n. 2, p. 337-368, jul./dez., 2005. Disponível em: http://seer.ufrgs.br/EmQuestao/article/view/124. Acesso em: 15 nov. 2013.

ARAÚJO, Eliany A.; DIAS, Guilherme A. A atuação do bibliotecário no contexto da Sociedade da Informação: os novos espaços de informação. In: Ciência da Informação e Biblioteconomia: novos conteúdos e espaços de atuação. Belo Horizonte: Editora UFMG, 2005. p. 111-122.

CAMPOS, Maria L. de A.; GOMES, Hagar E. Taxonomia e classificação: o princípio de categorização. DataGramaZero, v. 9, n. 4, ago. 2008. Disponível em: http://www.dgz.org.br/ago08/F I art.htm . Acesso em: 11 nov. 2013.

CHAUÍ, Marilena. Convite à filosofia. 12. ed. São Paulo: Ática, 2002.

CONSELHO FEDERAL DE BIBLIOTECONOMIA (CFB). Código de ética do profissional bibliotecário. Resolução CFB número 42, de 11 de janeiro de 2002.

CORTINA, Adela; NAVARRO, Emilio M. Ética. São Paulo: Loyola, 2005.

CUARTAS, Enriqueta G. D.; PESSOA, Maria L. de M. da V.; COSTA, Cosme G. da. Código de ética profissional do bibliotecário: 15 anos depois. BIBLOS - Revista do Instituto de Ciências Humanas e da Informação, v. 15, 2003. Disponível em: http://www.brapci.ufpr.br/documento. php?dd0=0000000045\&dd1=1a0f6 . Acesso em: 14 nov. 2013.

GOMES, H. F.; BOTTENTUIT, A. M.; OLIVEIRA, M. O. E. de. A ética na sociedade, na área da informação e da atuação profissional: o olhar da Filosofia, da Sociologia, da Ciência da Informação e do exercício profissional do bibliotecário no Brasil. Brasília: CFB, 2009

MARCONDES, Danilo. Textos básicos de ética. 3. ed. Rio de Janeiro: Jorge Zahar, 2008.

MISCHIATI, Ana C.; VALENTIM, Marta L. P. Reflexões sobre a ética e a atuação profissional do bibliotecário. Transinformação, Campinas, n. 17, p. 209-220, set./dez., 2005. Disponível em: < http://periodicos. puccampinas.edu.br/seer/index.php/transinfo/article/view/686> . Acesso em 18 nov. 2013.

RAJU, J.; RAJU, R. Descriptive and subject cataloguing. Oxford: Chandos, 2006.

SÁ, Antônio Lopes de. Ética profissional. 4. ed. São Paulo: Atlas, 2001.

SÁNCHEZ LUNA, B. E. Catalogación por matéria. In: FIGUEROA ALCÂNTARA, H. A.; RAMIREZ VELÁZQUEZ, C. A. Organización bibliográfica y documental. México: CUIB-UNAM, 2004.

SINGER, Peter. Ética prática. São Paulo: Martins Fontes, 2002.

TRISKA, Ricardo. Sociedade da informação e a gestão do conhecimento. PontodeAcesso, Salvador, v. 2, n. 1, p. 98-106, jun./jul. 2008. Disponível em: http://www.portalseer.ufba.br/index.php/revistaici/article/view/2668/1890 . Acesso em: 13 nov. 2013.

VERGUEIRO, W. C. S. Ética profissional versus ética social: uma abordagem sobre os mitos da biblioteconomia. Palavra-chave, São Paulo, n. 8, p. 8-11, 1994.

VIEIRA, Simone B. Indexação automática e manual: revisão de literatura. Ciência da Informação, v. 17, n. 1, p. 43-57, jun. 1988. Disponível em: http://revista.ibict.br/ciinf/index.php/ciinf/article/view/1391/1017. Acesso em: 14 nov. 2013. 


\section{Dados do autor}

\section{Edinei Antonio Moreno}

Discente do Programa de Pós-graduação em Gestão da Informação - PPGinfo, Mestrado Profissional em Gestão de Unidades de Informação - UDESC. Especialista em Gestão de Bibliotecas Escolares - UFSC. Especialista em

Educação para a Terceira Idade - Universidade Gama Filho. Bibliotecário formado pela Universidade Federal de Santa Catarina. Profissional Bibliotecário-documentalista do Instituto Federal de Santa Catarina. Tem experiência na área de Ciência da Informação, bibliotecas escolares e profissional da informação.

edineimoreno@gmail.com

Recebido - Received: 2014-02-25

Aceitado - Accepted : 2014-06-30

\section{(c)) EY}

This work is licensed under a Creative Commons Attribution 4.0

United States License.

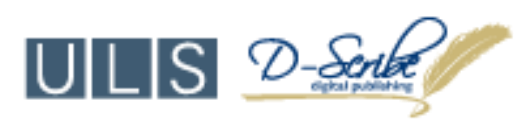

This journal is published by the University Library System of the University of Pittsburgh as part of its D-Scribe Digital Publishing Program and is cosponsored by the University of Pittsburgh Press. 